\title{
A Comparative Study on the Washback Effects of Teacher Feedback plus Intelligent Feedback versus Teacher Feedback on English Writing Teaching in Higher Vocational College
}

\author{
Jiachun Wang \\ Foreign Language College, Jiangxi Normal University, Nanchang, China
}

\begin{abstract}
For college students majoring in English, English writing is a relatively difficult project. How to effectively improve the English writing ability of students of English majors in vocational colleges is an important issue that every college teacher needs to pay attention to. As a teaching tool, the intelligent computer automated essay evaluation system can help students improve their English writing ability more objectively, efficiently and accurately. This paper employs the intelligent computer automated essay evaluation system as a teaching tool, taking college students as the research object, and carried out an 18-week online self-writing teaching experiment and traditional writing experiment. This paper conducts a comparative study on the washback effects of teacher feedback plus intelligent feedback versus teacher feedback on English writing teaching in higher vocational college, which provides a prominent research value and research significance for the reform and innovation of English writing teaching in higher vocational colleges.
\end{abstract}

Index Terms - higher vocational college, English writing ability, intelligent computer automated essay evaluation system, washback effect

\section{INTRODUCTION}

Language testing is an effective way to evaluate foreign language teaching and an important method to improve the quality of foreign language teaching. Language teaching and language testing are two inseparable factors, which are partners for mutual influence and mutual promotion. Language testing is an important tool for measuring and assessing students' academic performance, and it is also a teaching method and teaching tool. Teachers can get feedback from the language testing to understand the mastery of students' learning, and then regulate and improve their teaching plans. The performance of students in language testing can reflect the effectiveness of teaching to a certain extent (Tang \& Wu, 2011). The backwash effect is an important part of language testing that refers to the impact or reaction of the testing on language teaching and learning. It enables the learner to better describe the teaching objectives, and also stimulates the learners to build up self-evaluation and make management strategies in an effective manner (Wang, 2015).

Writing skills are one of the four basic skills of English learning and one of the key points of English teaching. However, at present, higher vocational college teaching have difficulty in timely feedback of teachers' evaluation, and because of the lack of students' motivation, English writing has always been a time-consuming and low-efficient teaching task. With the rapid development of computer technology and corpus linguistics, the intelligent computer automated essay evaluation system has entered the field of writing teaching. Compared with manual evaluation, automatic writing evaluation system is an energy-saving and economical tool in the final writing tests. The foreign language writing intelligent evaluation system originated in the 1960s, but it was introduced to China after decades. However, it has developed rapidly in recent years in China. The domestic intelligent computer automated essay evaluation system plays a prominent role in the formative assessment of English writing and the improvement of students' self-learning ability. The application of the intelligent computer automated essay evaluation system in English writing in higher vocational colleges is conducive to the construction of a combination of intelligent evaluation and teacher review, which helps to the exploration of an innovative efficient English writing teaching (Hou, 2015). This paper conducts a comparative study on the washback effects of teacher feedback plus intelligent feedback versus teacher feedback on English writing teaching in higher vocational college, which provides a prominent research value and research significance for the reform and innovation of English writing teaching in higher vocational colleges.

\section{A BriEf Introduction to InTElligent Computer Automated EsSAy Evaluation System}

Intelligent computer automated essay evaluation system originates in the 1960s. Early writing intelligent evaluation system was mainly used in large-scale writing marking. With the development of science and technology, various automatic evaluation systems have emerged. The most representative ones are Project Essay Grader (PEG), Intelligent Essay Assessor (IEA) and E- Rater. The PEG evaluation system mainly focuses on the structure of the article, such as 
fluency, grammar, vocabulary and punctuation, while ignores the content of the essay. The IEA evaluation system uses latent semantic analysis to grade the composition. The system not only analyzes the features of the composition, but also takes the structure associated with the composition into consideration. The E- Rater evaluation system grades the composition based on a large number of corpus text data, and adopts the natural language processing technology to evaluate the characteristics of the composition. The quality of the evaluation depends on the samples in the database (Xiong \& Wang, 2018).

The above intelligent writing evaluation systems have their own advantages and disadvantages. IEA and E- rater evaluate the composition comprehensively, while PEG mainly evaluates the surface features of the composition. In addition, some scholars in China are also actively exploring the establishment of an automatic writing evaluation system suitable for Chinese English learners. Professor Liang from Beijing Foreign Studies University successfully developed the EFL Essay Eval-uator1.0. This research has greatly contributed to the evaluation of large-scale English composition testing, but it is still necessary to perfect the writing system about writing habits and writing characteristics of language learners at home and abroad (Liang \& Wen, 2007).

Pigai.org is a mature online writing automatic evaluation system in recent years. The system not only provides students with independent writing training, but also offers instant feedback to students. The review and evaluation of students' essays is based on comparing students' essays to standard samples. The system can automatically check students' word spelling, vocabulary usage, grammatical context and other errors in quite a short time, and then it will offer suggestions for revision. In addition, the intelligent computer automated essay evaluation system also equipped with the functions of plagiarism detection, peer review, and excellent composition sharing. In a word, pigai.org is a relatively mature automatic composition evaluation system in China. This paper takes advantage of pigai.org as an auxiliary tool for English writing teaching in higher vocational college (He, 2013).

\section{LITERATURE REVIEW}

Looking back the domestic relevant literature review after 2010, the research on the intelligent computer automated essay evaluation system can be roughly divided into three parts: first one is the research on the reliability of the relevant system as well as the consistency between the system evaluation results and the teacher evaluation; the second one is the research on the influence of domestic intelligent writing evaluation system on college students' writing ability, especially the impact on college students' vocabulary, grammar and syntax in English writing; the third one is based on the application of intelligent writing evaluation system in college English writing teaching, with an aim to construct a new teaching method between intelligent computer automated essay evaluation system and college English writing teaching (Guan, 2018).

\section{A. Reliability Research on Intelligent Computer Automated Essay Evaluation System}

There are few literatures on the reliability of the intelligent computer automated essay evaluation system in China. According to the literatures, the intelligent computer automated essay evaluation system is quite reliable. Regarding this aspect, He Xuliang conducts a comparative study between intelligent writing evaluation system and teacher evaluation on 30 compositions. He finds that the pigai.org keeps lines with teacher evaluation, but higher in scores. Zhang Li et al. carries out a comparative study between the intelligent computer automated essay evaluation system and teacher evaluation on ten compositions with two sets of standard of evaluation about CET composition, which shows that both are highly correlated. In terms of the reliability of the "iwrite" system, Li Yanling and Tian Xiachun compared the grades of 645 essays between the "iwrite" system and teacher evaluation. The results manifest that "iwrite" system is so reliable that can be widely used in English teaching. The above research all carried out reliability analysis on the relevant system within a certain range, but the sample amount is not great enough and the types of compositions are not rich, therefore, the universality of the experimental results is not objective. All in all, the reliability analysis of domestic intelligent writing evaluation system under big data will be one of the focuses in the future.

\section{B. Feedback Contents and Effect Research on Intelligent Computer Automated Essay Evaluation System}

The research on feedback of pigai.org in China abounds, and the methodology on such topic concerns on quantitative research or qualitative research. Shi Xiaoling conducted an empirical study on the feedback and scores of pigai. org among 161 freshmen with questionnaires and interviews. Jiang Yan and Ma Wulin pointed out the challenges of pigai.org, for instance, it can only judge the writing ability from the language usage, and however, the semantic content cannot be judged. Hence, it cannot identify the errors in the writing content and expressions. He Xuliang concentrated on case study, in which he finds that pigai.org mainly focused on the appropriateness of vocabulary and grammar, but it lacks of the feedback on content, textual structure, rhetoric, logic and coherence. Hou Fen took 105 students from 3 English classes as research objects, and introduced pigai.org into English teaching. She conducted a 14-week teaching experiment and used questionnaires and case studies to explore the effectiveness of pigai.org in improving college students' English writing ability. Hu Xuewen took 45 non-English majors sophomores as the research object, examining the impact of online feedback towards college students. The data derived from the records of pigai.org, which was processed by SPSS 7.0. In summary, the domestic intelligent writing evaluation system pays much attention to the feedback of vocabulary, grammar and suggestion, lacking feedback on contents and coherence. Most students are 
satisfied with the intelligent computer automated essay evaluation system, believing it's helpful to improving their writing ability.

\section{Research on the Application of Intelligent Computer Automated Essay Evaluation System in English Writing Teaching in College}

The domestic intelligent writing evaluation system pays much attention to the feedback of vocabulary, grammar and suggestion, lacking feedback on contents and coherence. Therefore, the college English self-writing teaching mode should emphasize the combination of intelligent writing evaluation system and teacher feedback as well as peer review. Zhang Wenxia and Huang Jing believe that information technology should be highly integrated with English teaching, and adopt a combination of intelligent automatic evaluation, assistant evaluation, teacher evaluation, peer evaluation and self-evaluation. Yang Xiaoqiong and Dai Yuncai took 135 students as research objects to conduct an empirical study on the college English self-writing teaching model based on pigai.org with questionnaires, interviews and experiments. On the basis of combing the concepts, elements and models of learning analysis, and the main analytical tools and methods, Gan Ronghui and He Caishun expounded the application of intelligent techniques in foreign language teaching, that is, pigai.org can promote personalized teaching by case study. They put forward the concept of combining intelligent system with foreign language teaching, analyzing the feasibility of the application of intelligent system in foreign language teaching.

\section{RESEARCH DESIGN}

\section{A. Research Objective}

The English writing course in higher vocational colleges is an important part of the English majors in vocational colleges. The English writing ability directly reflects the students' English comprehensive ability. Improving the writing ability of English majors in vocational colleges is an important task for teachers. The research subject of this paper is sophomores majoring in business English in Jiangxi College of Foreign Studies. This paper aims to explore the effectiveness of teacher evaluation plus intelligent computer automated essay evaluation system and the differences with traditional teacher evaluation. Finally, it tries to explore a new way for English writing teaching in higher vocational college, reforming the traditional teaching method.

\section{B. The Situation of English Writing Ability of English Majors in Higher Vocational Colleges}

There are numerous problems in English Writing Ability of English Majors in Higher Vocational Colleges, which will be illustrated below.

(1) Seriously interfered with the mother language and frequently influenced by Chinglish.

(2) Regarding vocabulary, it is either too simple or there is a tendency of abuse or misuse.

(3) As for syntax, prepositions, conjunctions, articles, etc. are mixed together and grammatical errors abound.

(4) The structure is inconsistent, the sentences and the segments full of incoherence, and the article is too difficult to understand.

\section{Research Significance}

(1) In recent years, the effectiveness of domestic English teaching has gotten attention from all walks of life. The problems in English writing teaching have gradually emerged. The development of writing ability has become the most difficult part of English teachers and learners in China, especially in recent years, the greatly expansion of colleges has brought a shortage of college English teachers to various universities, which makes the problem of improving English writing ability of college students more serious (Liu, 2003: 257-261). The results of this research will offer guiding suggestions to English majors in higher vocational college.

(2) The "University English Curriculum Teaching Requirements (Trial)" promulgated and implemented in January 2004 clearly stated that in the new era, "English teaching based on computer and network should be promoted". The advantage of artificial intelligence lies in its objective, high efficiency and high accuracy (Jin, 2017: 34-35). For example, the popularity of pigai.org is the best statement of artificial intelligence. Compared with teacher evaluation, the intelligent computer automated essay evaluation system is better in marking quickly, giving out specific feedback, pointing out plagiarism, highlighting the important clauses and phrases. This study attempts to study the intrinsic influence of the evaluation mode of the pigai.org on students' English writing, and how to improve students' English writing ability. It can provide relevant theoretical and research support for the effective usage of the intelligent computer automated essay evaluation system similar to the pigai.org.

\section{Research Questions}

(1) What is the difference between teacher feedback plus intelligent computer automated essay evaluation system feedback and traditional teacher feedback on students' English writing?

(2) What's the effectiveness of intelligent computer automated essay evaluation system plus teacher evaluation in improving English majors' writing ability in higher vocational colleges?

\section{E. Research Subject}


The research subject of this paper is sophomores majoring in business English in Jiangxi College of Foreign Studies. The number is 105, among them, the number of students in Business English Class 5 is 52, and the number of Class 8 is 53, the age ranging from 19-21 (see Table 4.5). The 18-week teacher feedback + intelligent feedback teaching method was conducted in the experimental class (Class 5), and the control class (Class 8) received 18 weeks of traditional teacher feedback.

They all major in business English and have the same teacher in writing course; last but not least, they never use pigai.org. Therefore, their objective conditions are basically the same. This paper conducted a writing test at the beginning of the semester to test that if the students in Class 5 and Class 8 are nearly the same in writing ability before the experiment. After five experiments, is there a significant difference between the experimental class and control class in the writing scores?

TABLE 4.5

THE DETAILS OF RESEARCH SUBJECTS

\begin{tabular}{|l|c|c|c|c|c|}
\hline \multicolumn{1}{|c|}{ Subject } & Class & Time & Grade & Number & Total \\
\hline experimental class & 5 & 18 week & sophomore & 52 & \multirow{2}{*}{105} \\
\hline control class & 8 & 18 week & sophomore & 53 & \\
\hline
\end{tabular}

\section{F. Research Methodology and Tool}

The research employs SPSS 16.0 system, and the research methodology used is descriptive statistics and independent sample T-test. For the experimental group, the students' English writing ability was comprehensively evaluated by pigai.org. Based on the comprehensive consideration of the students' English foundation, English learning attitude and learning methods, combined with the relevant data, students' English writing ability was confirmed. Therefore, the positive role of pigai.org plays in improving college students' English writing ability is explored.

In details, through the data comparison and analysis of the writing grades of the experimental class and the control class, we can better confirm the effectiveness and scope of the online English composition evaluation system, and then the advancement and intelligence of the intelligent computer automated essay evaluation system can be explored.

\section{EXPERIMENTAL PROCEDURES}

\section{A. An Analysis of Pre-test Exam}

In the second half of 2018, I took over an integrated course for sophomores in class 5 and class 8 . The total number of students is 105 . At the beginning of the semester, I asked students to write a composition about the topic "Do you think it is necessary for college students to do a part-time job in summer vacation?" They should finish the writing within 40 minutes and the words of composition is about 120-180 words. This research marked the composition according to the CET-4 writing standards and did an independent sample T-test based on the student's writing scores to ensure that the writing ability of these two classes is nearly the same. Afterwards, the 18-week teacher feedback + intelligent feedback method was conducted in class 5, while the class 8 received an 18-week traditional teacher feedback method (see Table 5.1).

TABLE 5.1

THE INDEPENDENT SAMPLE T-TEST RESUlTS OF PRE-TEST EXAM IN Class 5 AND CLASS 8

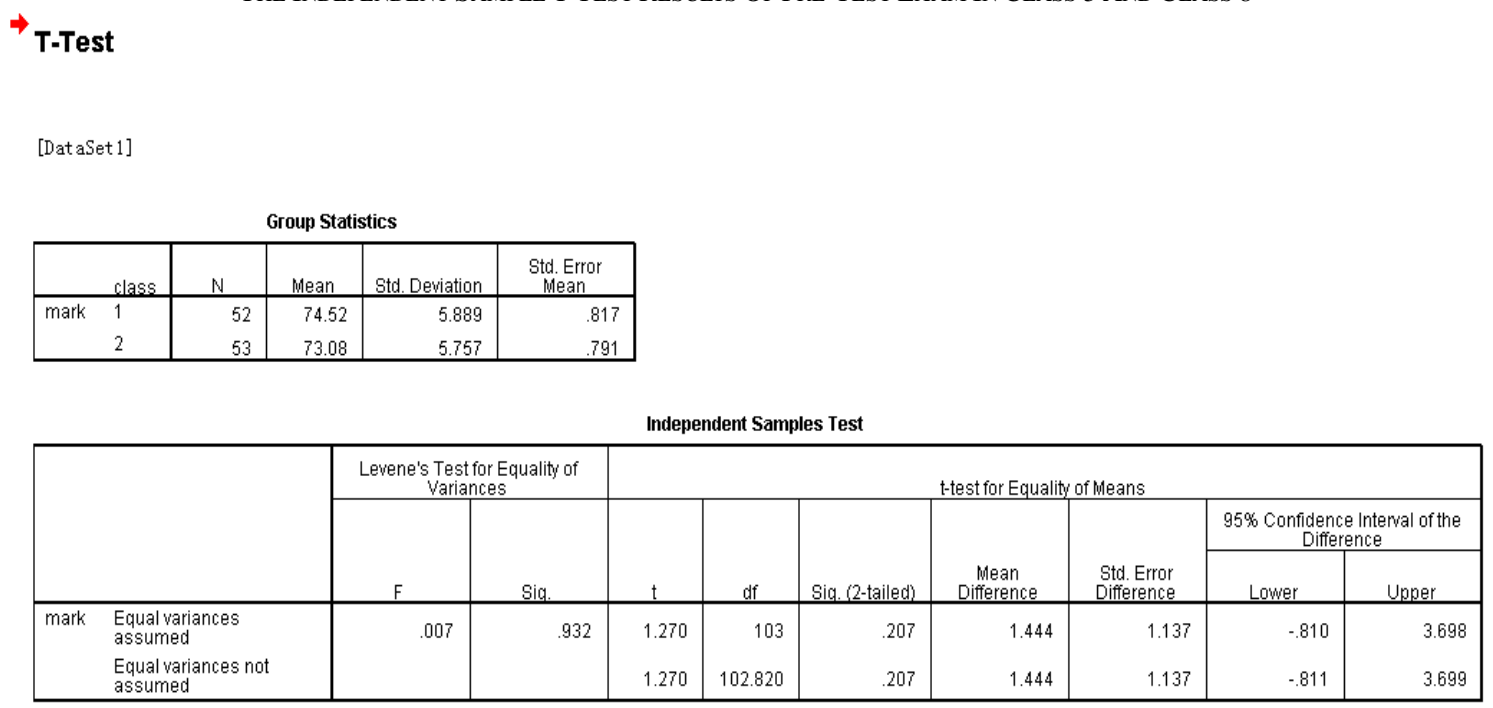

From table 5.1, we can see that sig. is 0.207 ( $\mathrm{p}>0.05$ ), which shows that there is no difference between class 5 and class 8 in English writing, that is to say, the English writing ability of these two classes are almost the same. Therefore, 
we can infer that if the grades between two classes are significantly different after 18-week experiment, we can confirm that different teaching methods and feedback can bring out different results.

\section{B. Experimental Procedures}

Firstly, I am familiar with and master the usage of the pigai.org, and this research will instruct students how to use the pigai.org and tell them the precautions of the network platform. Secondly, this experiment will ask the students to finish the first English composition on pigai.org within limited time, and then ask them to complete the online submission according to the relevant requirements. There are five units in the integrated course for business English majors within 18 weeks, which attach five topic-relevant compositions at the end of each unit. Thirdly, this research asks students to finish one argumentative essay, one expository composition and one essay with cartoon, which are similar to the requirements of CET-4. Finally, this experiment will list the writing outline before each task, and students are asked to take the expressions and phrases of each unit into consideration. The experiment takes about 18 weeks, and I will draw conclusions in the end.

\section{Experimental class}

The experimental class takes the pigai.org as the teaching tool, and the teaching procedures are shown below (see Chart 5.2.1): teacher gives out the writing task, and then students finish the writing and submit online, finally, students modifies the composition for many times and teacher evaluates their compositions as well as giving out some feedback.

\section{Control class}

The control class takes the traditional English writing teaching method (see Chart 5.2.2): teacher assigns English writing task, and then students finish the writing and hand in, finally, teacher evaluate their compositions and gives comments in class.

\section{Final exam:}

The final exams of Jiangxi College of Foreign Studies are evaluated by all the teachers in the integrated course. The personal information of the students is hidden in the papers, ensuring the objectivity of the scores. The final part of this final exam is English writing whose the topic is "The importance of hand writing".

At last, I will compare the writing scores between the pre-test and post-test exams, and the conclusion will be made.

CHART 5.2.1

The ENGLish Writing Teaching In THE EXPERIMENTAL Class:

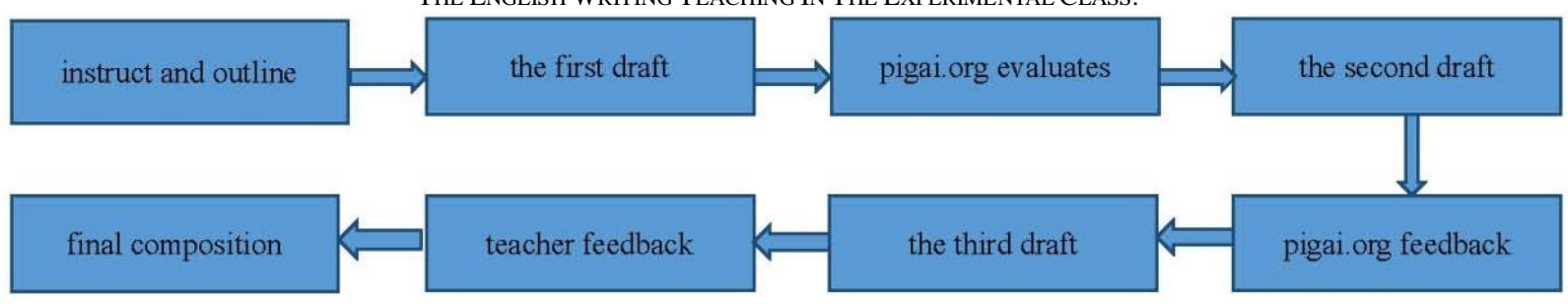

CHART 5.2.2

THE ENGLISH WRITING TEACHING IN THE CONTROL Class:

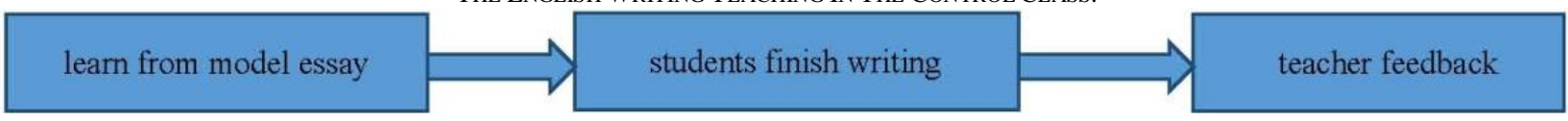

\section{Formulate Writing Evaluation Criteria}

This research adopts the rating standard of CET-4 to evaluate the compositions in class 5 on pigai.org, so the same in class 8. In order to facilitate the division, this paper transfers the total score into 100 points, keeping in line with the total score of 15 points in CET, and so on. The following table is the evaluation standard of CET-4.

TABLE 5.3

THE EVALUATION STANDARD OF CET-4

\begin{tabular}{|c|l|}
\hline score & \multicolumn{1}{c|}{ evaluation standard } \\
\hline $\mathbf{1 3 - 1 5}$ & $\begin{array}{l}\text { The expression is clear, the text is fluent and coherent, and there are basically no grammar errors. There are } \\
\text { only a few small mistakes. }\end{array}$ \\
\hline $\mathbf{1 0 - 1 2}$ & The expression is clear, the text is coherent, but there are some grammar errors. \\
\hline $\mathbf{7 - 9}$ & The expression is not clear, and the text is not coherent; there are many errors, some are serious in particular. \\
\hline $\mathbf{4 - 6}$ & The expression is confused, as well as lacking coherence; there are a lot of grammar errors. \\
\hline $\mathbf{1 - 3}$ & $\begin{array}{l}\text { The words are unclear, ideologically disordered; there are many fragments or most sentences are wrong, and } \\
\text { some are serious errors. }\end{array}$ \\
\hline $\mathbf{0}$ & No answer, or only a few isolated words; or the essays are irrelevant to the subject. \\
\hline
\end{tabular}

The figure below shows the evaluation of the experimental class by the pigai.org. 


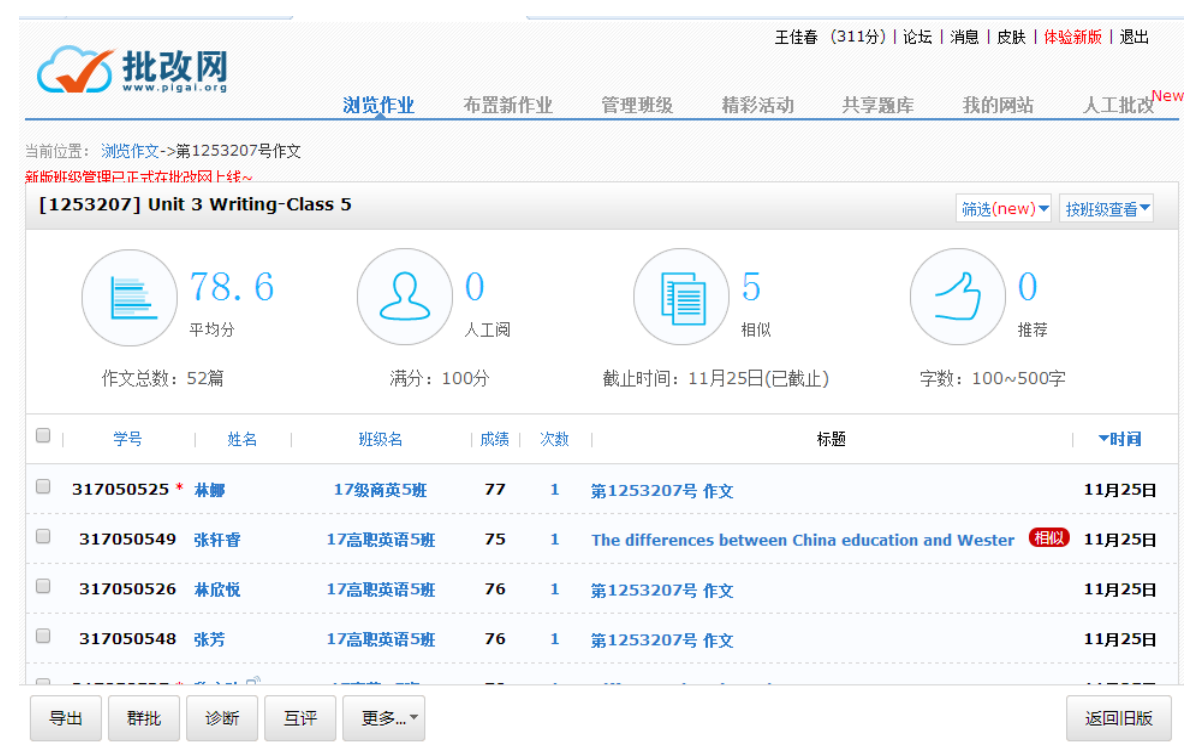

\section{RESEARCH RESUlt AND DisCUSSION}

This paper employs SPSS 16.0 system as the analytical tool, and the results of independent sample T-test is shown below (see table 6.1)

TABLE 6.1

COMPARISON OF POST-TEST SCORES BETWEEN STUDENTS IN EXPERIMENTAL ClaSS AND CONTROL ClaSS

\section{$\rightarrow$ T-Test}

[DataSet 1]

\begin{tabular}{|c|c|c|c|c|c|}
\hline \multicolumn{6}{|c|}{ Group Statistics } \\
\hline & class & $\mathrm{N}$ & Mean & Std. Deviation & $\begin{array}{c}\text { Std. Error } \\
\text { Mean }\end{array}$ \\
\hline \multirow[t]{2}{*}{ mark } & 1 & 52 & 78.63 & 3.763 & .522 \\
\hline & 2 & 53 & 76.49 & 4.313 & 592 \\
\hline
\end{tabular}

\begin{tabular}{|c|c|c|c|c|c|c|c|c|c|c|}
\hline & & \multicolumn{2}{|c|}{$\begin{array}{c}\text { Levene's Test for Equality of } \\
\text { Variances }\end{array}$} & \multicolumn{7}{|c|}{ t-test for Equality of Means } \\
\hline & & \multirow[b]{2}{*}{$\mathrm{F}$} & \multirow[b]{2}{*}{ Siq. } & \multirow[b]{2}{*}{$t$} & \multirow[b]{2}{*}{ df } & \multirow[b]{2}{*}{ Siq. (2-tailed) } & \multirow[b]{2}{*}{$\begin{array}{c}\text { Mean } \\
\text { Difference }\end{array}$} & \multirow[b]{2}{*}{$\begin{array}{l}\text { Std. Error } \\
\text { Difference }\end{array}$} & \multicolumn{2}{|c|}{$\begin{array}{l}95 \% \text { Confidence Interval of the } \\
\text { Difference }\end{array}$} \\
\hline & & & & & & & & & Lower & Upper \\
\hline mark & $\begin{array}{l}\text { Equal variances } \\
\text { assumed }\end{array}$ & .755 & .387 & 2.712 & 103 & .008 & 2.144 & .790 & .576 & 3.712 \\
\hline & $\begin{array}{l}\text { Equal variances not } \\
\text { assumed }\end{array}$ & & & 2.716 & 101.619 & .008 & 2.144 & .789 & .578 & 3.710 \\
\hline
\end{tabular}

From table 6.1, we can see that sig. is $0.008(\mathrm{p}<0.05)$, which shows that there is significantly difference between class 5 and class 8 in English writing, that is to say, the English writing ability of class 5 is improved a lot after 18-week experiment, which proves that teacher feedback plus intelligent feedback overwhelms the traditional teacher feedback in English writing teaching.

\section{CONCLUSION}

The traditional English composition evaluation method is a teacher feedback method, which has little effect on improving the students' English composition. The student's role is passive in such teaching method. The motivation to modify the composition is not great, and their willingness to self-learning is not strong. As a kind of auxiliary teaching tool, pigai.org avoids the shortages and defects of traditional teacher feedback, helping students in higher vocational college improve their English writing ability more effectively, efficiently and accurately.

The design of this research mainly employs the independent sample t-test, after 18 weeks of writing feedback, analyzing the differences between the English writing ability of the experimental class and the control class from the pre-test and post-test scores of the experiment, thus confirming the effectiveness of teacher feedback + intelligence feedback. The purpose of this experiment is to change the role of students in writing, so that students can independently 
modify their compositions repeatedly, improving students' enthusiasm for writing and modifying their compositions, and try to offer a new teaching method for the existing writing evaluation method for English writing teaching in higher vocational colleges.

\section{REFERENCES}

[1] Guan Shanshan. (2018). A Review of the Application Research of Intelligent Writing Evaluation System in College English Writing Teaching. New Course Research, (10):102-105.

[2] He Xuliang. (2013). The Reliability and Validity of the evaluation of pigai.org. Modern Educational Technology, (5):64-67.

[3] Hou Fen. (2015). The Application of Online Automatic Writing Evaluation System in College English Writing Teaching--Take pigai.org as an Example. China Education Information, (16):24-27.

[4] Jin Yan. (2017). The Application of Artificial Intelligence in the Writing and Translation in CET-4 and CET-6. Link \& Think, (4): 24-27.

[5] Liu Runqing. (2003). Efficient English Teaching. Foreign Language Teaching and Research, 35.

[6] Liang Maocheng, Wen Qiufang. (2007). A Review and Implication of Automatic Writing Evaluation System Abroad. Computer-assisted Foreign Language Education, (5):18-24.

[7] Tang Jinlan, Wu Yian. (2011). A Review of the Applied Research on Online English Writing Automatic Evaluation System. Foreign Language Teaching and Research, 43(2): 273-282.

[8] Wang Boran, Jin Tan, Zhao Wen. (2015). Automatic Writing Evaluation Research and Practice for 50 years - from Isolation, Cooperation to Interaction. Foreign Language Teaching Press, (5):50-56.

[9] Xiong Songrong, Wang Yang. (2018). Application of Automatic Writing Evaluation System in College English Writing Teaching. Journal of Hubei Correspondence University, (17): 68-72.

Jiachun Wang was born in Guangdong, China in 1993. She is a postgraduate student in the Foreign Language College of Jiangxi Normal University in China. Her research interests include theory and practice in Systemic Functional Linguistics. She has published academic papers respectively entitled An Analysis of Fortress Besieged from the Perspective of Pragmatics and An Experiential Metafunctional Analysis of Poetry in Song Dynasty ---- Take Ru Meng Ling as an Example. 